\title{
Peroxisome proliferator-activated receptor- $\alpha$ activator fenofibrate prevents high-fat diet-induced renal lipotoxicity in spontaneously hypertensive rats
}

\author{
Seok Joon Shin ${ }^{1}$, Ji Hee Lim ${ }^{1}$, Sungjin Chung ${ }^{1}$, Dong-Ye Youn ${ }^{2}$, Hyun Wha Chung ${ }^{1}$, Hyung Wook Kim ${ }^{1}$, \\ Jeong-Hwa Lee ${ }^{2}$, Yoon Sik Chang ${ }^{1}$ and Cheol Whee Park ${ }^{1}$
}

We investigated the effects of a high-fat (HF) diet and peroxisome proliferator-activated receptor (PPAR)- $\alpha$ activation on the intrarenal lipotoxicity associated with the renin-angiotensin system (RAS) and oxidative stress using spontaneously hypertensive (SHR) rats. Male SHR and Wistar-Kyoto (WKY) rats at 8 weeks of age were fed either a normal-fat diet or an HF diet without or with fenofibrate treatment for 12 weeks. Severe intrarenal lipid accumulation was noted in the SHR rats fed an HF diet than in WYK rats fed an HF diet $(P<0.05)$. This lipid accumulation was associated with a $70 \%$ decrease in renal PPAR $\alpha$ expression in SHR rats, whereas an HF diet increased the expression of PPAR $\alpha$ in WKY rats by threefold. An HF diet also activated intrarenal, not systemic, RAS and induced oxidative stress associated with reduced nitric oxide (NO) bioavailability. By contrast, fenofibrate attenuated weight gain, fat mass and insulin resistance. Fenofibrate recovered HF diet-induced decreases in intrarenal PPAR $\alpha$ expression and fat accumulation, and abolished intrarenal RAS activation and oxidative stress in SHR-HF animals $(P<0.01)$. These activities conferred protection against increased blood pressure (BP), glomerulosclerosis and renal inflammation. Intrarenal free fatty acid and triglyceride concentrations were positively correlated with angiotensin II $(\gamma=0.63,0.36)$ and $24-\mathrm{h}$ urinary 8-hydroxy-deoxyguanosine $(\gamma=0.36,0.39)$, and negatively correlated with PPAR $\alpha$ contents $(\gamma=-0.47,-0.44 ; P<0.05)$. An HF diet-induced lipotoxicity by depletion of intrarenal PPAR $\alpha$ aggravated BP and renal inflammation as a result of intrarenal RAS activation and oxidative stress. Therefore, intervention with PPAR $\alpha$ activators can effectively prevent diet-induced renal lipotoxicity in hypertensive rats.

Hypertension Research (2009) 32, 835-845; doi:10.1038/hr.2009.107; published online 31 July 2009

Keywords: obesity; oxidative stress; PPAR $\alpha$; renal inflammation; renin-angiotensin system

\section{INTRODUCTION}

Currently, the prevalence of hypertension and chronic renal disease continues to increase among obese individuals. ${ }^{1,2}$ It has been suggested that the development and progression of hypertension in an obese patient induces the activation of the systemic renin-angiotensin system (RAS) and the sympathetic nervous system. ${ }^{3,4}$ In addition, it increases asymmetric dimethylarginine concentrations and vascular tone created by the reduced bioavailability of nitric oxide (NO) owing to increased oxidative stress. ${ }^{5,6}$ Recent reports have demonstrated that it is not the systemic but the local (tissue specific) RAS activation that causes hypertension and renal damage ${ }^{7-9}$ associated with local oxidative stress. ${ }^{10-12}$ It has been shown that oxidative stress in kidneys of diabetic animals, measured by the electron spin resonance imaging technique, ${ }^{10}$ high-performance liquid chromatography ${ }^{13}$ and immunohistochemistry, ${ }^{14}$ can be ameliorated by RAS inhibition.
The local accumulation of lipids, lipotoxicity, may cause an excess of lipids in the form of triglycerides (TGs) or free fatty acids (FFAs) that affect non-adipose tissues and lead to cell dysfunction or death. ${ }^{8,15}$ Several studies have demonstrated that lipotoxicity is associated with the direct toxic effects of fatty acids or the products of their metabolites, with adenosine triphosphate deficiency, fatty acid-induced apoptosis and increased production of reactive oxygen species. ${ }^{15}$ In kidneys, lipid accumulation with lipotoxicity may explain the insidious fibrosis and cellular decay that is characteristic of nephropathy in the metabolic syndrome.

Peroxisome proliferator-activated receptor (PPAR)- $\alpha$, a subfamily of the nuclear receptor transcriptional factors, is involved in almost all aspects of lipid metabolism, including uptake, binding and oxidation of fatty acids, lipoprotein assembly and lipid transport. ${ }^{16,17}$ Furthermore, it has been implicated in vascular inflammation and blood

${ }^{1}$ Division of Nephrology, Department of Internal Medicine, The Catholic University of Korea, Seoul, Korea and ${ }^{2}$ Department of Biochemistry, The Catholic University of Korea, Seoul, Korea

Correspondence: Dr CW Park, Division of Nephrology, Department of Internal Medicine, The Catholic University of Korea, no. 505 Banpo-Dong, Seocho-Ku, Seoul 137-040, the Republic of Korea.

E-mail: cheolwhee@hanmail.net

Received 17 March 2009; revised 12 May 2009; accepted 9 June 2009; published online 31 July 2009 
pressure $(\mathrm{BP})$ regulation by nuclear factor- $\mathrm{\kappa} \mathrm{B}$, transforming growth factor (TGF)- $\beta /$ Smad and mitogen-activated protein kinase pathways, ${ }^{18,19}$ and by angiotensin II (AT-II)-induced oxidative stress. ${ }^{20}$ In kidneys, PPAR $\alpha$ expression, often seen in proximal tubules and thick ascending limb, could contribute to a dietary lipid-induced gene expression of peroxisomes and mitochondrial $\beta$-oxidation proteins in these segments. ${ }^{21,22}$ Fenofibrate, a specific PPAR $\alpha$ ligand, participates in the AT-II-dependent BP regulation associated with antagonizing AT-II effects by attenuating angiotensin type 1-mediated but enhancing angiotensin type 2-mediated hemodynamic effects. It does so through NO production, oxidative stress and cytochrome P450-derived eicosanoids in the kidney. ${ }^{23,24}$ Therefore, in this study, we investigated the role of fenofibrate on renal lipotoxicity associated with hypertension and renal inflammation using spontaneously hypertensive (SHR) rats fed a high-fat (HF) diet.

\section{METHODS}

\section{Experimental methods}

The Animal Care Committee of the Catholic University of Korea approved the experimental protocol. Seven-week-old male SHR (SLC, Nakaizu, Japan) and Wistar-Kyoto (WKY) rats were used for all experiments. After 1 week of acclimation, 8-week-old rats were fed either a normal-fat (NF) (WKY-NF and SHR-NF, $n=6$ ) or an HF diet (WKY-HF and SHR-HF, $n=8$ ) and drank water ad libitum for 12 weeks. The NF diet (Samyang, Wonju, Korea) consisted of $0.23 \% \mathrm{NaCl}, 16 \% \mathrm{kcal}$ fat, $58 \% \mathrm{kcal}$ carbohydrate and $26 \% \mathrm{kcal}$ protein, with $25 \mathrm{~g} \%$ of soybean. The HF diet (no. 12451 Research Diet, New Brunswick, NJ, USA) consisted of $0.23 \% \mathrm{NaCl}, 45 \% \mathrm{kcal}$ fat, $35 \% \mathrm{kcal}$ carbohydrate and $20 \%$ $\mathrm{kcal}$ protein, with $25 \mathrm{~g} \%$ of soybean. There were no differences in the concentration of $\mathrm{K}^{+}$and $\mathrm{Na}^{+}$between the NF and HF diets. In addition, the SHR-HF rats were treated with fenofibrate (SHR-HF feno; $20 \mathrm{mg} \mathrm{kg}^{-1}$ day $^{-1}$ in the chow, $n=8$ ) from 8 weeks of age for 12 weeks. For measurement of 24-h urinary and creatinine clearance, rats were placed in individual rat metabolic cages (Tecniplast, Gazzada, Italy). Rat body weight and systolic BP (SBP) were measured every 4 weeks. BP was assessed by a noninvasive tail-cuff system (IITC Life Science, Woodland Hills, CA, USA) in conscious rats. Intraperitoneal glucose tolerance and glycated hemoglobin $\left(\mathrm{HbA}_{1 \mathrm{c}}\right)$ were measured at the end of the study. After 12 weeks, kidneys were rapidly dissected and stored in buffered formalin (10\%) for subsequent immunohistochemical analyses.

\section{Measurement of serum and urine parameters}

All blood samples were obtained after a 6-h fast. Blood glucose was measured by an Accu-check meter (Roche Diagnostics, St Louis, MO, USA). $\mathrm{HbA}_{1 \mathrm{c}}$ (Bayer Healthcare LLC, Indianapolis, IN, USA), serum total cholesterol, TG, high-density lipoprotein-cholesterol, low-density lipoprotein-cholesterol, FFA and insulin concentrations (Wako, Osaka, Japan) were measured by autoanalyzers. The homeostasis model assessment for insulin resistance index was calculated as follows: fasting glucose $\left(\mathrm{mmoll}^{-1}\right) \times$ fasting insulin $\left(\mathrm{mUl}^{-1}\right) /$ 22.5. ${ }^{22}$ Plasma renin activity (Renin-RIA BEAD, SRL, Tokyo, Japan) and serum (Diagnostic Systems Laboratories, Webster, TX, USA) and 24-h urine (Cayman Chemical, Ann Arbor, MI, USA) aldosterone levels were measured using an RIA kit.

\section{Assessment of renal function and renal oxidative stress}

The 24-h urinary protein excretion was measured by immunoassay (Bayer, Elkhart, IN, USA). At week 12, plasma creatinine concentrations were measured using an autoanalyzer (Beckman Instruments, Fullerton, CA, USA). Plasma and urinary sodium, potassium and osmolarity were measured by the ADVIA 1650 System (Bayer, Tarytown, NY, USA). Transtubular potassium gradient (TTKG) was calculated as follows: TTKG $=$ urinary potassium/(plasma osmolarity/urinary osmolarity)/plasma potassium. To evaluate oxidative stress, we measured 24-h urinary 8-hydroxy-deoxyguanosine (8-OH-dG; OXIS Health Products, Portland, OR, USA) and 8-epi-PGF $2 \alpha$ (Northwest Life Science Specialties, Vancouver, WA, USA). Serum and total urinary $\mathrm{NO}_{3}{ }^{-}+\mathrm{NO}_{2}{ }^{-}$ excretion (NOx) were quantified using the Nitric Oxide Assay Kit (BioVision, Mountain View, CA, USA).

\section{Measurement of kidney lipids, AT II and PPAR $\alpha$}

Kidney lipids were extracted using the method of Bligh and Dyer with slight modifications, as previously described (Waco, Osaka, Japan).22,25 The AT-II concentration in the kidneys was measured using a commercial ELISA kit (SPIBIO, Bretonneux, France), with the lower detection limit of $0.5-1.5 \mathrm{pg} \mathrm{ml}^{-1}$, as previously described. ${ }^{26}$ We also performed western blot analysis of PPAR $\alpha$ in the kidney using anti-PPAR $\alpha$ (1:1000; provided by Dr Akita Sugawara, Department of Medicine, Tokuhu University, Japan).

\section{Light microscope study}

Kidney samples were collected after a systemic perfusion with phosphatebuffered saline; they were then fixed in $4 \%$ paraformaldehyde. The mesangial matrix and glomerular tuft areas were quantified for each glomerular crosssection as previously reported. ${ }^{21,22}$ More than 30 glomeruli, cut through the vascular pole, were counted per kidney, and the average of measured areas was used for analysis. To evaluate the effect of the HF diet on lipid accumulation in the kidney, we performed oil red $\mathrm{O}$ staining on frozen renal tissue.

\section{Immunohistochemistry for renin, AT-II, osteopontin, ED-1, PPAR $\alpha$, TGF- $\beta$, TUNEL and 8-OH-dG}

We performed immunohistochemistry for renin, AT-II, osteopontin, ED-1, TUNEL (TdT-mediated dUTP nick end labeling) and TGF- $\beta 1$. Kidney sections were incubated overnight in a humidified chamber at $4{ }^{\circ} \mathrm{C}$ with anti-renin (1:8000; provided by Dr Kirsten Madsen, Department of Medicine, University of Florida, Gainesville, FL, USA), anti-AT-II (1:200; Peninsula Labs, San Carlos, CA, USA), anti-ED-1 (1:1000; Serotec, Raleigh, NC, USA), anti-osteopontin (1:2000; MPIIIB10, obtained from the Developmental Studies Hybridoma Bank, University of Iowa, Iowa City, IA, USA), anti-TGF- $\beta 1$ (1:100; Santa Cruz Biotechnology, Santa Cruz, CA, USA) and 8-OH-dG as a marker for oxidative DNA damage (1:100; JalCA, Shizuoka, Japan). For quantification of the proportional areas of staining, approximately 20 views $(\times 200$ magnification, Olympus BX-50; Olympus Optical, Tokyo, Japan) were randomly located in the renal cortex and corticomedullary junction of each slide in a blind manner (Scion Image Beta 4.0.2, Frederick, MD, USA).

\section{RNA extraction and quantitative real-time PCR}

Total RNA was extracted from the kidneys of all rats with RNA-Bee (TEL-TEST, Texas, TX, USA). cDNA was synthesized from $2 \mu \mathrm{g}$ of total RNA using the AccuPower Cycle Script (dN6) (Bioneer, Daejeon, Korea). The mRNA level of genes involved in RAS activation was measured by quantitative real-time PCR using a cDNA template and appropriate primers (Table 1). Quantitative realtime PCR was performed using the IQ5 Real-Time PCR detection System and IQ TM SYBR Green Supermix (Bio-Rad Laboratories, Hercules, CA, USA).

Table 1 Primers sequences used for quantification of gene expression by real-time PCR and the resulting product size

\begin{tabular}{llc}
\hline Gene & Primers & Size (bp) \\
\hline Renin & 5'-TTCTCTCCCAGAGGGTGCTA-3' & 211 \\
& 5'-CCCTCCTCACACAACAAGGT-3' & \\
Angiotensinogen & 5'-CACGGACAGCACCCTATTTT-3' & 103 \\
ACE & 5'-GCTGTTGTCCACCCAGAACT-3' & \\
& 5'-GAGCCATCCTTCCCTTTTTC-3' & 154 \\
18S rRNA & 5'-GGCTGCAGCTCCTGGTATAG-3' & \\
& 5'-CGCGGTTCTATTTTGTTGGT-3' & 219 \\
PPAR $\alpha$ & 5'-AGTCGGCATCGTTTATGGTC-3' & \\
& 5'-CTCCCTCCTTACCCTTGGAG-3' & \\
& 5'-GCCTCTGATCACCACCATTT-3' & 124
\end{tabular}

Abbreviations: ACE, angiotensin-converting enzyme; PPAR $\alpha$, peroxisome proliferator-activated receptor- $\alpha$. 
a Body weight (gm)
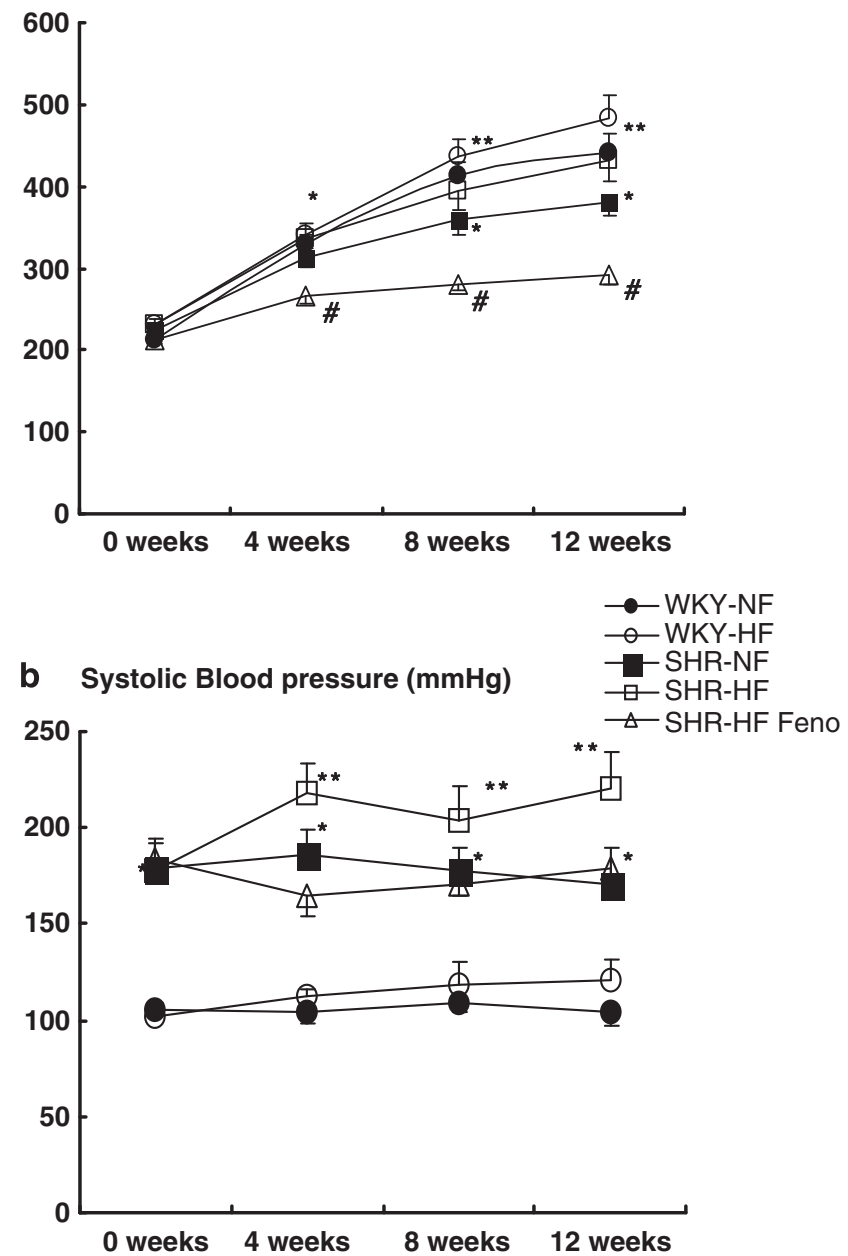

Figure 1 Changes of body weight (a) and systolic blood pressure (b) during the experimental period in Wistar-Kyoto (WKY) and spontaneously hypertensive (SHR) rats with a normal-fat diet (WKY-NF and SHR-NF) or a high-fat diet without treatment (WKY-HF and SHR-HF) or with fenofibrate treatment (SHR-HF Feno). ${ }^{*} P<0.05,{ }^{*} P<0.01$ and ${ }^{\#} P<0.001$ vs. the other groups.
Relative levels of all PCR products were determined after normalization to an endogenous $18 \mathrm{~S}$ rRNA control.

\section{Statistical analyses}

Data are expressed as means \pm s.d. The differences between the groups were examined for statistical significance using two-way analysis of variance with Bonferroni's correction (SPSS 11.5, Chicago, IL, USA). Non-normally distributed data were analyzed with the nonparametric unpaired Mann-Whitney test. Correlation coefficients were calculated using Spearman's rank-order test. A $P<0.05$ was considered as a statistically significant difference.

\section{RESULTS}

Body and peri-epididymal fat weight

Both WKY rats and SHR rats on the HF diet were heavier than those on an NF diet after 4 weeks of treatment. These weight gains were maintained until the end of the study (Figure 1a). The peri-epididymal fat of WKY-HF and SHR-HF rats (5.9 \pm 1.0 and $5.4 \pm 1.0 \mathrm{~g}$, respectively) was also heavier than that of the WKY-NF and SHR-NF rats $(3.9 \pm 0.3$ and $2.5 \pm 0.2 \mathrm{~g}$, respectively; $P<0.05$ and 0.01 , respectively; Table 2). There was no difference in kidney/body weight ratios among all three groups. However, the SHR-HF feno rats showed significant decreases in body and peri-epididymal fat weights $(2.2 \pm 0.3 \mathrm{~g})$ compared with the other groups during the entire experimental period $(P<0.001)$. Less food intake was observed in SHR-HF and SHR-HF feno animals, compared with the rats on the NF diet $(P<0.05)$; however, no difference in food intake was observed between these two groups.

\section{Systolic BP}

As expected, the SBP of the SHR-NF and SHR-HF rats was higher throughout the entire experimental period compared with that of WKY-NF and WKY-HF rats $(P<0.01$ and 0.001 , respectively; Figure $1 \mathrm{~b})$. At the end of the experiment, the SBP of WKY-NF and WKY-HF rats, as well as that of SHR-NF and SHR-HF animals, was $104.1 \pm 7.0,121.4 \pm 9.7,170.9 \pm 17.9$ and $220.8 \pm 19.0 \mathrm{~mm} \mathrm{Hg}$, respectively. SBP tended to be higher in WKY-HF rats, but this difference was not statistically significant. However, the SBP of the SHR-HF animals was significantly higher than that of the SHR-NF group at 12 weeks. Interestingly, the elevated SBP decreased to the level of the SHR-HF group in the SHR-HF feno animals $(171.3 \pm 7.2 \mathrm{~mm} \mathrm{Hg})$.

Table $2 \mathrm{HbA1c}$, plasma insulin level, HOMA $\mathrm{IR}_{\mathrm{R}}$ and serum lipid profiles at 12 weeks in the WKY and SHR groups with a normal-fat (NF) or high-fat (HF) diet

\begin{tabular}{|c|c|c|c|c|c|}
\hline Parameters & $W K Y-N F$ & $W K Y-H F$ & $S H R-N F$ & $S H R-H F$ & SHR-HF feno \\
\hline Diet $\left(\mathrm{g} \mathrm{day}^{-1}\right.$ ) & $23.3 \pm 2.9$ & $21.2 \pm 3.3$ & $20.4 \pm 1.3$ & $16.0 \pm 3.0^{a}$ & $15.2 \pm 0.9^{a}$ \\
\hline Water intake $\left(\mathrm{ml}\right.$ day $\left.^{-1}\right)$ & $24.3 \pm 7.7$ & $28.6 \pm 5.65 .9$ & $23.6 \pm 5.8$ & $33.8 \pm 8.0$ & $27.6 \pm 1.32 .2$ \\
\hline Epi wt (g) & $3.9 \pm 0.3$ & $\pm 1.0^{\mathrm{a}}$ & $2.5 \pm 0.2^{b}$ & $5.4 \pm 1.0^{\mathrm{a}}$ & $\pm 0.3^{b}$ \\
\hline $\mathrm{HbA1c}(\%)$ & $3.3 \pm 0.1$ & $3.6 \pm 0.1$ & $3.4 \pm 0.2$ & $3.4 \pm 0.2$ & $3.1 \pm 0,1^{a}$ \\
\hline Insulin $\left(\left.p g\right|^{-1}\right)$ & $0.99 \pm 0.49$ & $1.32 \pm 0.41$ & $1.12 \pm 0.44$ & $1.46 \pm 0.36$ & $0.95 \pm 0.08$ \\
\hline $\mathrm{HOMA}_{I R}$ & $0.60 \pm 0.28$ & $0.68 \pm 0.36$ & $0.53 \pm 0.16$ & $0.65 \pm 0.20$ & $0.34 \pm 0.15^{a}$ \\
\hline Total cholesterol (mg per $100 \mathrm{ml}$ ) & $107.2 \pm 5.5$ & $109.4 \pm 14.2$ & $109.8 \pm 9.1$ & $115.9 \pm 11.0$ & $85 \pm 4.0^{\mathrm{a}}$ \\
\hline Triglyceride (mg per $100 \mathrm{ml}$ ) & $26 \pm 4$ & $39 \pm 14$ & $40 \pm 12$ & $30 \pm 9$ & $39 \pm 11$ \\
\hline LDL-cholesterol (mg per 100 ml) & $5.5 \pm 1.0$ & $6.1 \pm 2.2$ & $5.4 \pm 1.0$ & $6.6 \pm 0.9$ & $4.4 \pm 0.7$ \\
\hline HDL-cholesterol (mg per $100 \mathrm{ml}$ ) & $37.5 \pm 1.0$ & $35.1 \pm 1.7$ & $28.1 \pm 2.2^{a}$ & $20.5 \pm 1.3^{b}$ & $35.0 \pm 1.7$ \\
\hline Free fatty acid $\left(\mu \mathrm{Eq} \mathrm{I}^{-1}\right)$ & $408 \pm 61$ & $420 \pm 52$ & $407 \pm 80$ & $536 \pm 61^{c}$ & $419 \pm 110$ \\
\hline Adiponectin $\left(\mathrm{ng} \mathrm{ml}^{-1}\right)$ & $7.4 \pm 2.1$ & $7.0 \pm 1.6$ & $8.9 \pm 2.9$ & $7.6 \pm 0.8$ & $13.3 \pm 0.9^{d}$ \\
\hline
\end{tabular}

Abbreviations: Epi wt, peri-epididymal fat weight; HbAlc, hemoglobin Alc; HDL, high-density lipoprotein; HOMA $\mathrm{IR}_{\text {, }} \mathrm{HOMA}$-insulin resistance index; LDL, low-density lipoprotein; SHR, spontaneously hypertensive rats; WKY, Wistar-Kyoto rats; Wt, weight.

a $P<0.05$ vs. the other groups.

b $P<0.01$ vs. WKY-NF and WKY-HF groups.

${ }^{c} P<0.01$ vs. the other groups.

$\mathrm{d} P<0.001$ vs. the other groups. 
Plasma $\mathrm{HbA}_{1 \mathrm{c}}$, insulin concentrations, homeostasis model assessment for insulin resistance index and intraperitoneal glucose tolerance test

There were no statistically significant differences in $\mathrm{HbA}_{1 \mathrm{c}}$, insulin concentrations and homeostasis model assessment for insulin resistance among the study groups. However, the insulin concentration and homeostasis model assessment for insulin resistance of the SHRHF group were higher compared with those of the SHR-NF group (Table 2). Interestingly, for intraperitoneal glucose tolerance test, the SHR-HF group showed dramatically increased blood glucose levels from 30 to $120 \mathrm{~min}(P<0.01$; Figure 2$)$. These increases were significantly decreased in the SHR-HF feno group from 60 to $120 \mathrm{~min}$ $(P<0.001$, Figure 2$) . \mathrm{HbA}_{1 \mathrm{c}}$ was significantly decreased in the SHRHF feno animals $(P<0.05)$.

Serum adiponectin, serum and intrarenal lipid concentrations and lipid staining in the kidney

There were no differences in serum total cholesterol, low-density lipoprotein-cholesterol, TG and adiponectin concentrations among all groups (Table 2). The high-density lipoprotein-cholesterol levels in SHR-HF rats had the lowest values among all groups $(P<0.01)$. The FFA levels in the SHR-HF group were higher than those of the other groups $(P<0.01)$. Fenofibrate treatment significantly decreased FFA and increased serum high-density lipoprotein-cholesterol and adiponectin concentrations in the SHR-HF feno group $(P<0.001)$. Direct measurement of the lipid contents in the kidney showed that the renal concentrations of TG and FFA were increased in WKY-HF rats on an HF diet $(P<0.05$, respectively, Figures $3 \mathrm{a}$ and $\mathrm{b})$. Interestingly, a greater lipid accumulation was observed in the SHR-HF group than in WKY-HF rats $(P<0.05)$. Of great interest, increases in TG and FFA levels in the kidneys returned to normal in the SHR-HF feno group $(P<0.01)$.

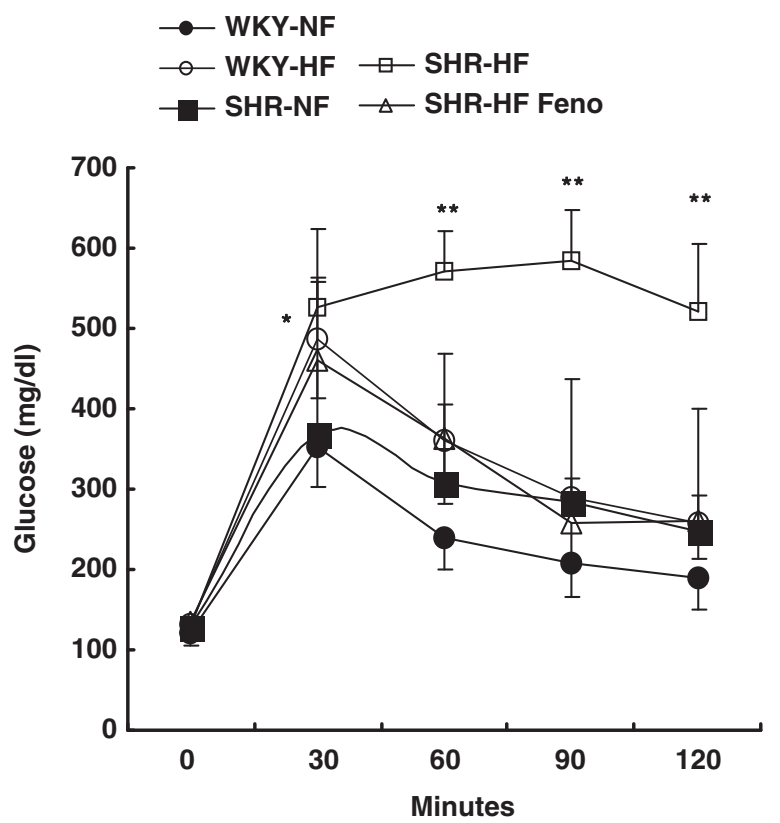

Figure 2 Intraperitoneal glucose tolerance test at 12 weeks in the WistarKyoto (WKY) and spontaneously hypertensive (SHR) groups with a normal-fat diet (WKY-NF and SHR-NF) or a high-fat diet without treatment (WKY-HF and SHR-HF) or with fenofibrate treatment (SHR-HF feno). ${ }^{\star} P<0.05$ and ${ }^{* *} P<0.01$ vs. the other groups.
Protein and mRNA expressions of PPAR $\alpha$ in the kidney

To evaluate the direct relationship between HF diet-induced lipotoxicity and PPAR $\alpha$ expression, we measured the protein and mRNA levels of PPAR $\alpha$ in the kidneys. Despite the gains in body weight and fat mass in the WKY-HF rats and in the SHR-HF group, the expression of PPAR $\alpha$ in kidneys was increased in the WKY-HF group by threefold compared with that in WKY-NF rats. By contrast, the enhanced PPAR $\alpha$ expression in SHR-NF rats was markedly decreased in the SHR-HF group by about $70 \%$ (Figure 4). Of great interest was the observation that fenofibrate treatment completely restored the suppressed protein and mRNA levels of PPAR $\alpha$ in the kidneys to the levels of those of SHR-NF animals.

Plasma renin activity, aldosterone, urine and renal functional parameters

There were no differences in serum creatinine, PRA or serum aldosterone levels among the groups (Table 3). However, 24-h urinary

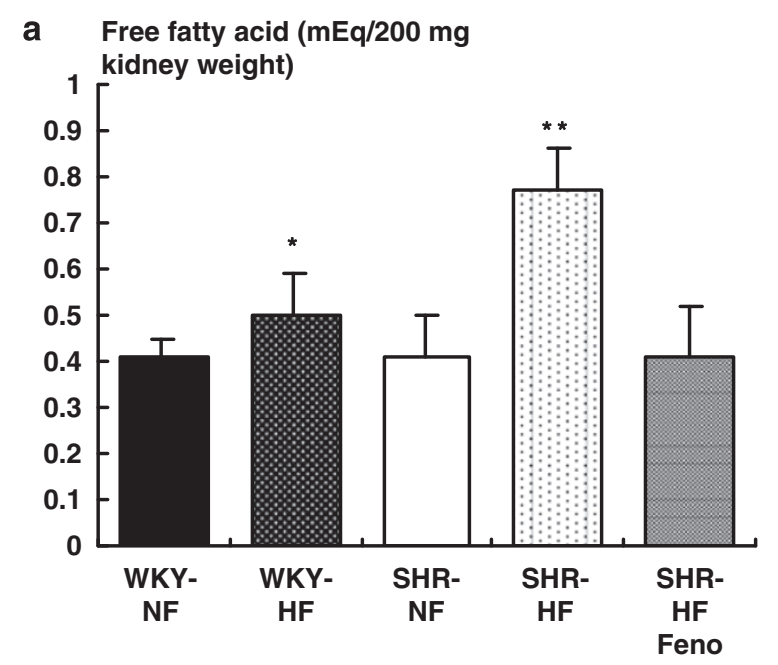

b Triglycerides $(\mathrm{mEq} / 200 \mathrm{mg}$ kidney weight)

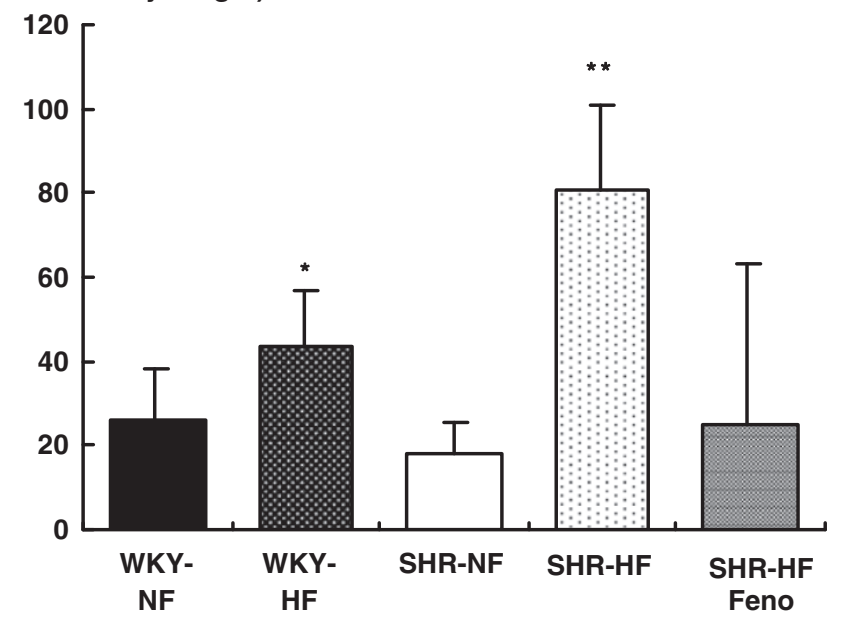

Figure 3 Intrarenal triglyceride (a) and free fatty acid (b) concentrations at 12 weeks in the Wistar-Kyoto (WKY) and spontaneously hypertensive (SHR) groups with a normal-fat diet (WKY-NF and SHR-NF) or a high-fat diet without treatment (WKY-HF and SHR-HF) or with fenofibrate. ${ }^{*} P<0.05$ vs. the other groups; ${ }^{* *} P<0.01$ vs. the other groups, except the WKY-HF group $(P<0.05)$. 

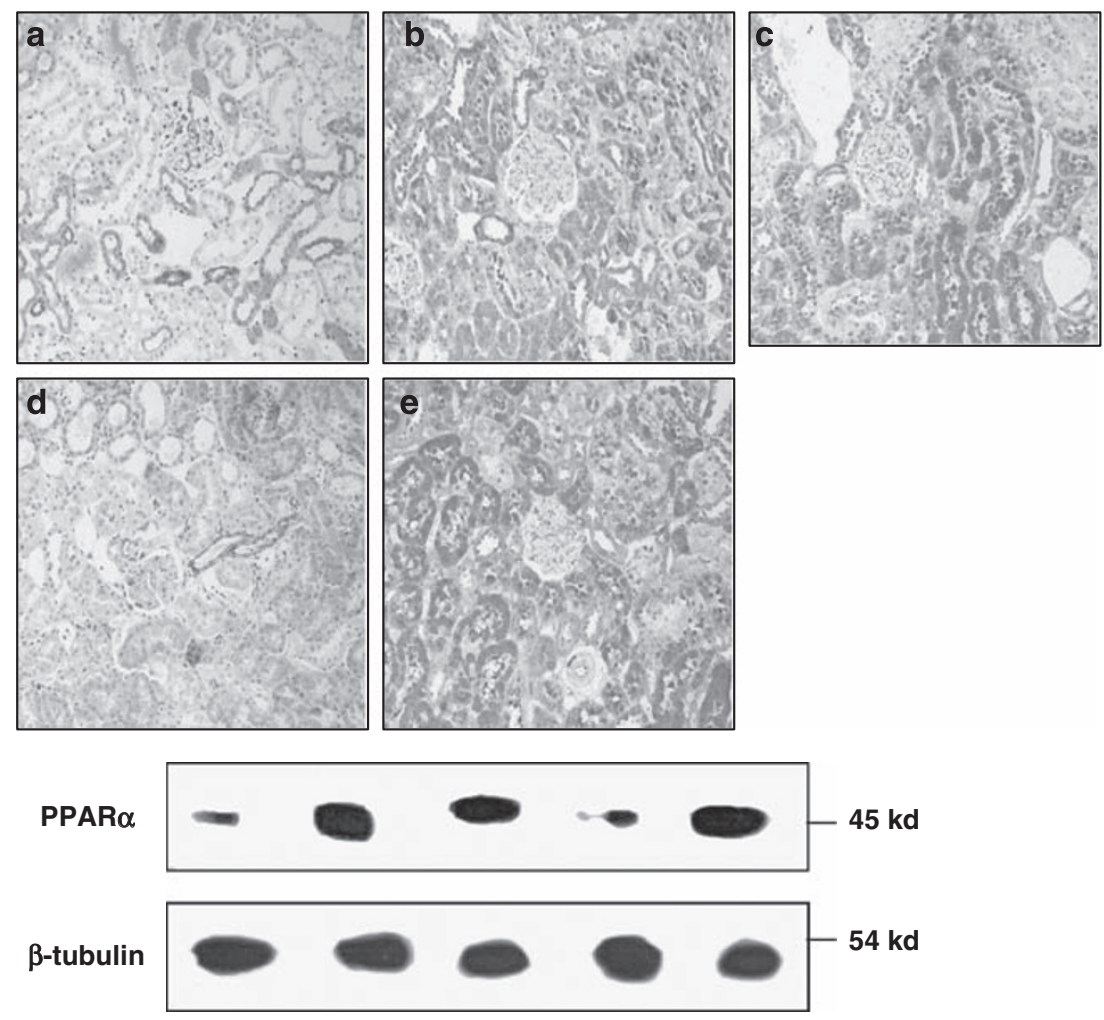

f

PPAR $\alpha / 18 S$ rRNA mRNA (folds)

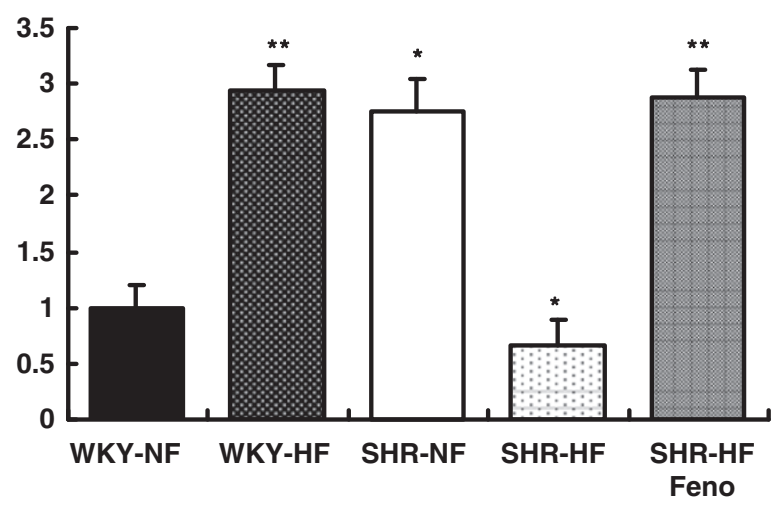

Figure 4 Immunohistochemical staining for peroxisome proliferator-activated receptor (PPAR) $\alpha$ in the renal cortex in the Wistar-Kyoto (WKY) and spontaneously hypertensive (SHR) groups with a normal-fat diet (WKY-NF; a and SHR-NF; c) or a high-fat diet without treatment (WKY-HF, SHR-HF; b and d, respectively) or with fenofibrate (SHR-HF feno) treatment (e). Western blot analysis of PPAR $\alpha$ and tubulin and PPAR $/ 18 \mathrm{~s}$ rRNA ratios (f) were determined by real-time PCR in whole kidneys; ${ }^{*} P<0.05$ and ${ }^{* *} P<0.01$ vs. the other groups. A full color version of this figure is available at the Hypertension Research journal online.

protein excretion was increased in the SHR-HF group compared with that in other groups $(P<0.05)$. The SHR-HF group had the lowest 24-h urinary $\mathrm{Na}^{+}$concentration and the highest TTKG level among all groups (Table 3). Interestingly, fenofibrate treatment in SHR-HF animals demonstrated a normalization of 24 -h urinary protein, $\mathrm{Na}^{+}$ concentration and TTKG level (Table 3).

\section{Expression of renin and AT-II}

The HF diet was associated with an increase in the number and intensity of renin-expressing cells in the juxtaglomerular area of the kidneys (Figure 5). In the kidneys of SHR-HF animals, immunoreactivity for AT-II and renal tissue AT-II concentration were significantly increased (Figure 5, $P<0.01$ ). By contrast, no such change was observed in WKY-HF rats. For the SHR-HF group, treatment with fenofibrate significantly lowered urinary aldosterone, immunoreactivity for renin and AT-II, and tissue AT-II levels $(P<0.01)$.

Quantification of mRNA expression of renin, angiotensinogen and angiotensin-converting enzyme

As shown in Figure 5, renin, angiotensin and angiotensin-converting enzyme mRNA expressions in SHR-HF rats were increased by 1.5-, 2.1- and 3.7-fold compared with those in the SHR-NF group after normalization to $18 \mathrm{~S}$ rRNA expression. However, no such changes 
Table 3 Urine and serum biochemical characteristics and renal function parameters at 12 weeks in the WKY and SHR groups with normal-fat (NF) or high-fat (HF) diet

\begin{tabular}{|c|c|c|c|c|c|}
\hline Parameters & $W K Y-N F$ & $W K Y-H F$ & $S H R-N F$ & $S H R-H F$ & SHR-HF feno \\
\hline Creatinine (mg per 100 ml) & $66 \pm 0.05$ & $0.70 \pm 0.05$ & $0.66 \pm 0.05$ & $0.62 \pm 0.05$ & $0.61 \pm 0.05$ \\
\hline Ccr (ml per min per $100 \mathrm{~g} w \mathrm{t})$ & $0.51 \pm 0.12$ & $0.57 \pm 0.12$ & $0.37 \pm 0.11$ & $0.36 \pm 0.12$ & $0.43 \pm 0.09$ \\
\hline Urine protein $\left(\mathrm{mg} \mathrm{day}^{-1}\right)$ & $8.2 \pm 4.9$ & $13.3 \pm 4.8$ & $12.8 \pm 3.3$ & $29.0 \pm 4.0^{a, b}$ & $8.6 \pm 5.6$ \\
\hline Urine $\mathrm{Na}^{+}\left(\mathrm{mEq} \mathrm{day}^{-1}\right)$ & $70 \pm 13$ & $58 \pm 21$ & $61 \pm 14$ & $48 \pm 13^{c, d}$ & $91 \pm 10^{\mathrm{a}, \mathrm{b}}$ \\
\hline TTKG (\%) & $6.83 \pm 0.29$ & $5.83 \pm 0.41$ & $7.17 \pm 0.98$ & $8.22 \pm 0.67^{a}$ & $3.60 \pm 0.51^{b}$ \\
\hline PRA (ng ml $\left.\mathrm{l}^{-1} \mathrm{~h}^{-1}\right)$ & $7.6 \pm 6.9$ & $8.8 \pm 5.4$ & $7.2 \pm 4.3$ & $7.3 \pm 5.1$ & $11.6 \pm 1 / 4$ \\
\hline Serum aldosterone $\left(\mathrm{pg} \mathrm{ml^{-1 }}\right)$ & $303 \pm 73$ & $351 \pm 103$ & $328 \pm 121$ & $348 \pm 123$ & $264 \pm 105$ \\
\hline
\end{tabular}

Abbreviations: $\mathrm{CrCl}$, creatinine clearance (ml per min $100 \mathrm{~g}$ body weight); PRA, plasma renin activity; TTKG, transtubular potassium gradient; SHR, spontaneously hypertensive rats; WKY, Wistar-Kyoto rats; Wt, weight.

a $P<0.05$ vs. WKY-NF and WKY-HF group.

b $P<0.05$ vs. SHR-NF, and $P<0.01$ vs. WKY-NF and WKY-HF group.

c $P<0.05$ vs. WKY-NF and SHR-NF group.

$\mathrm{d} P<0.01$ vs. SHR-HF feno group.
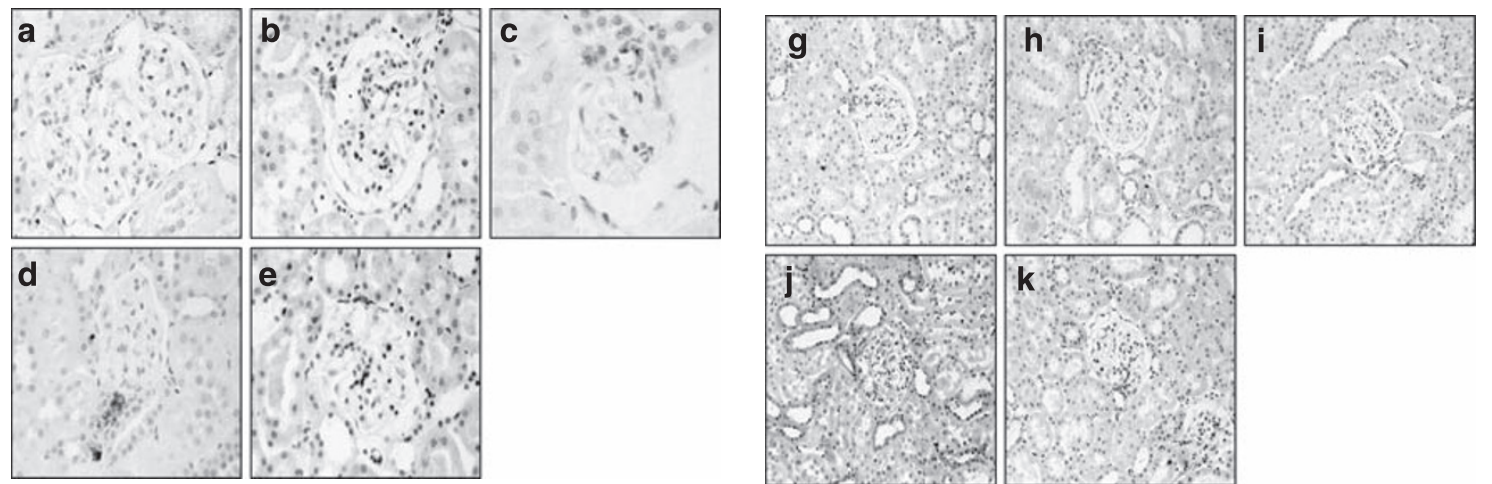

f

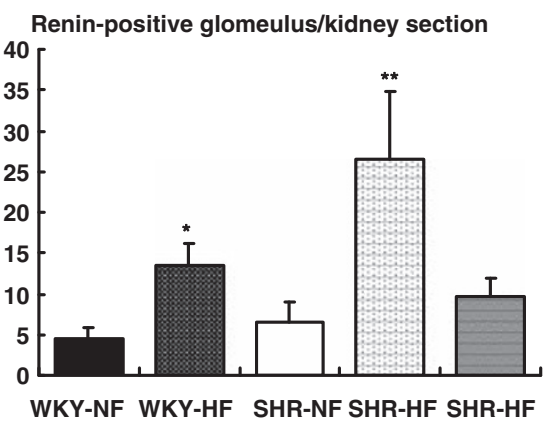

I Angiotensin II immunostain (folds)
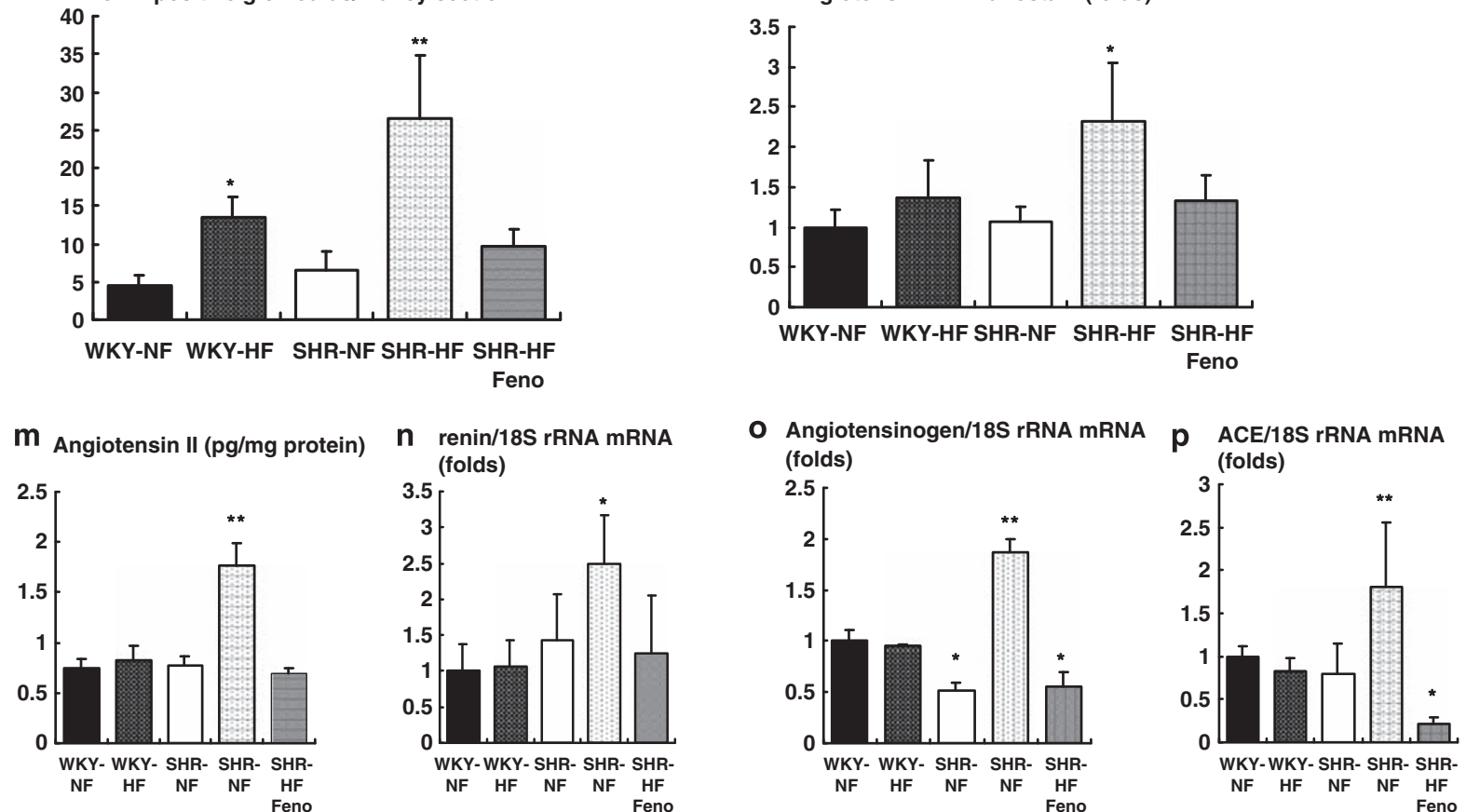

Figure $5 \mathrm{Immunohistochemical} \mathrm{staining} \mathrm{for} \mathrm{renin} \mathrm{in} \mathrm{the} \mathrm{renal} \mathrm{cortical} \mathrm{glomeruli} \mathrm{and} \mathrm{for} \mathrm{angiotensin} \mathrm{II} \mathrm{in} \mathrm{the} \mathrm{cortex} \mathrm{in} \mathrm{the} \mathrm{Wistar-Kyoto} \mathrm{(WKY)} \mathrm{and}$ spontaneously hypertensive (SHR) groups with a normal-fat diet (WKY-NF and SHR-NF) (a and $\mathbf{g}, \mathbf{c}$ and $\mathbf{i}$, respectively) or a high-fat (HF) diet without treatment (WKY-HF, SHR-HF, respectively) ( $\mathbf{b}$ and $\mathbf{h}, \mathbf{d}$ and $\mathbf{j}$, respectively) or with fenofibrate (SHR-HF feno) treatment (e and $\mathbf{k}$ ). Representative immunostains for renin (a-e, magnification, $\times 400)$ and angiotensin II (g-k, magnification, $\times 200)$. Quantitative assessment of renin ( $\mathbf{f})$ and angiotensin II (I) immunoreactivity in the WKY and SHR groups with a normal-fat (WKY-NF and SHR-NF) or an HF diet treated without (WKY-HF and SHR-HF) or with fenofibrate (SHR-HF feno). (m) Kidney angiotensin II concentration in the study groups. The renin/18s RNA (n), angiotensin/18s RNA (o) and angiotensin-converting enzyme (ACE)/18S rRNA (p) ratios were determined by real-time PCR in whole kidneys in the WKY and SHR groups with an NF diet (WKY-NF and SHR-NF) or an HF diet without treatment (WKY-HF and SHR-HF) or with fenofibrate treatment (SHR-HF feno). The increase factor is expressed in comparison with that in the WKY-NF group. ${ }^{*} P<0.05$ and ${ }^{* *} P<0.01$ vs. the other groups. A full color version of this figure is available at the Hypertension Research journal online. 
Table 4 Renal histopathological changes at 12 weeks in the WKY and SHR groups with normal-fat (NF) or high-fat (HF) diet

\begin{tabular}{|c|c|c|c|c|c|}
\hline Parameters & $W K Y-N F$ & WKY-HF & SHR-NF & $S H R-H F$ & SHR-HF feno \\
\hline \multicolumn{6}{|c|}{ Immunostaining in the kidney (folds) } \\
\hline Osteopontin & $1.0 \pm 0.3$ & $3.7 \pm 1.0^{\mathrm{a}}$ & $1.1 \pm 0.5$ & $6.77 \pm 1.3^{b}$ & $1.5 \pm 0.3$ \\
\hline \multicolumn{6}{|l|}{ Number of ED-1 cells } \\
\hline in glomerulus & $0.7 \pm 0.8$ & $1.3 \pm 0.7$ & $1.0 \pm 0.8$ & $2.1 \pm 1.3^{c}$ & $0.8 \pm 0.5$ \\
\hline \multicolumn{6}{|l|}{ Number of TUNEL (+) } \\
\hline in glomerulus & $0.4 \pm 0.6$ & $2.5 \pm 0.9^{c}$ & $1.1 \pm 0.5$ & $7.2 \pm 2.4^{a}$ & $2.1 \pm 1.3^{c}$ \\
\hline
\end{tabular}

Abbreviations: Ms, mesangial; TGF- $\beta 1$, transforming growth factor $\beta 1$; SHR, spontaneously hypertensive rats; WKY, Wistar-Kyoto rats.

a $P<0.01$ vs. the other groups.

${ }^{\mathrm{b}} P<0.001$ vs. the other groups.

${ }^{c} P<0.05$ vs. the other groups.

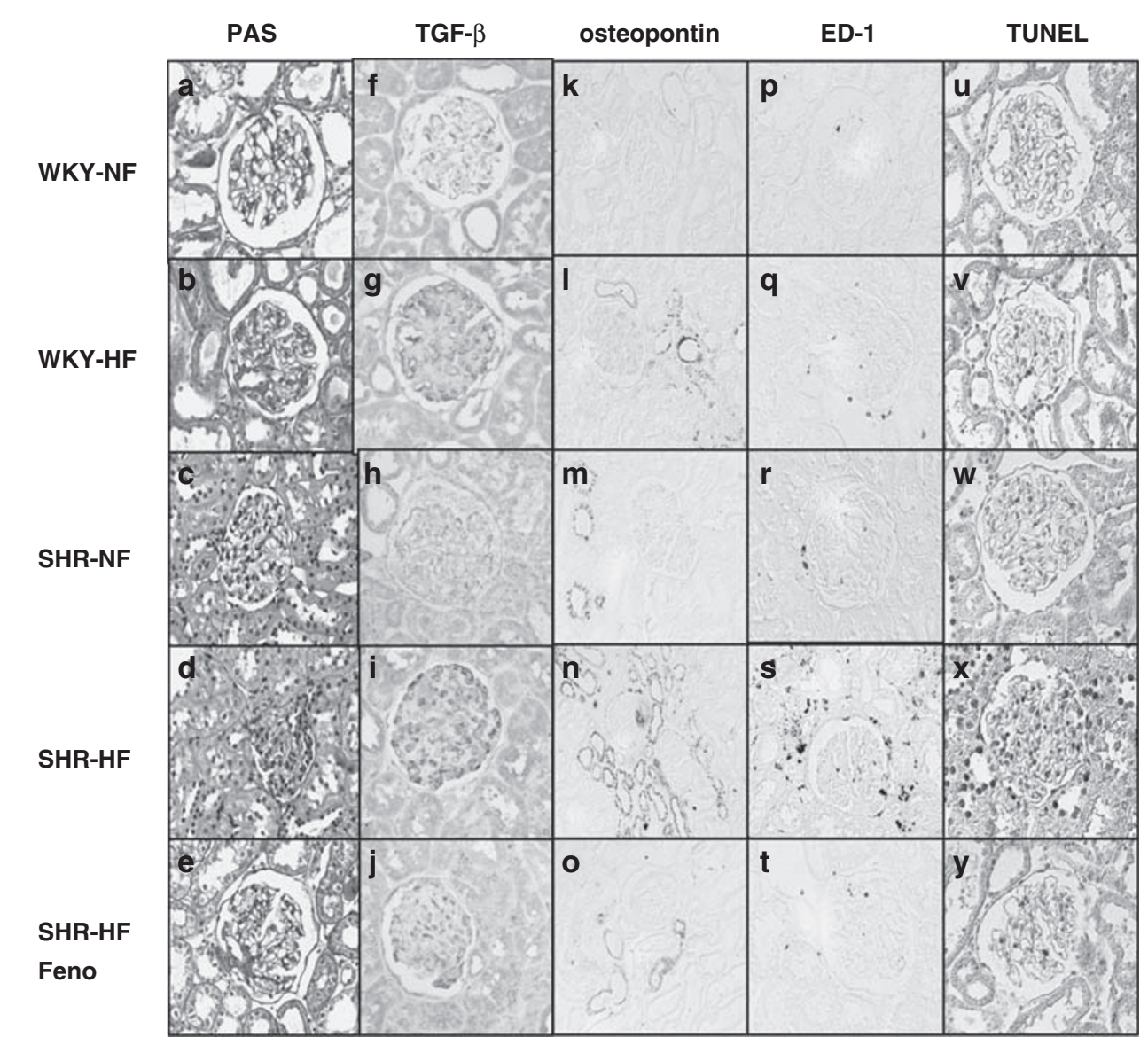

Figure 6 Representative pictures for the glomerulus in the kidneys (a-e, PAS) to assess glomerular expansion and sclerosis, and immunohistochemical staining for transforming growth factor (TGF)- $\beta 1(\mathbf{f}-\mathbf{j})$, osteopontin ( $\mathbf{k}-\mathbf{0})$, ED-1 (p-t) and TUNEL (TdT-mediated dUTP nick end labeling; $\mathbf{u}-\mathbf{y}$, magnification, $\times 200$ ) in the renal cortical tissue in the WKY and SHR groups with a normal-fat diet (WKY-NF; a, f, $\mathbf{k}, \mathbf{p}$ and $\mathbf{u}$, SHR-NF; $\mathbf{c}, \mathbf{h}, \mathbf{m}, \mathbf{r}$ and $\mathbf{v}$ ) or a high-fat diet without treatment (WKY-HF; $\mathbf{b}, \mathbf{g}, \mathbf{I}, \mathbf{q}$ and $\mathbf{w}, \mathrm{SHR}-\mathrm{HF} ; \mathbf{d}, \mathbf{i}, \mathbf{n}, \mathbf{s}$ and $\mathbf{x}$ ) or with fenofibrate (SHR-HF feno; $\mathbf{e}, \mathbf{j}, \mathbf{o}, \mathbf{t}$ and $\mathbf{y}$ ). A full color version of this figure is available at the Hypertension Research journal online.

were observed between the rats in the WKY-NF and WKY-HF groups. These increases were significantly smaller in the SHR-HF feno group. Combined with the immunostaining results of renin and AT-II and tissue AT-II, these data indicated that intrarenal RAS activation in the kidneys of SHR-HF rats was ameliorated by fenofibrate (Figure 5).
Expression of TGF- $\beta 1$, osteopontin, ED-1, TUNEL and renal histology Glomeruli from WKY-HF, SHR-NF and SHR-HF rats exhibited increased fractional mesangial areas compared with those from WKY-NF rats (Table 4, Figure 6). Immunohistochemical analysis demonstrated that the kidneys from WKY-HF and SHR-HF rats 
contained more TGF- $\beta 1$ compared with those from WKY-NF and SHR-NF rats $(P<0.05)$. The expansion of the mesangial area along with TGF- $\beta 1$ expression was noted in SHR-HF animals $(P<0.01)$. There was an increase in the expression of osteopontin in the glomeruli and interstitium of the cortex of the rats fed with an HF diet compared with that in the rats fed an NF diet $(P<0.05$ and $P<0.01$, respectively). The expression of osteopontin in the renal cortex was more pronounced in the SHR-HF group $(P<0.01)$. The number of ED-1-positive cells was two- to threefold higher in the intra- and peri-glomerular areas of the SHR-HF group compared with that in the other groups $(P<0.01)$. The number of apoptotic cells (TUNEL) in the glomerulus of the SHR-HF group was increased compared with that in the other groups $(P<0.001)$. We also found that fenofibrate significantly reduced glomerular expansion, TGF- $\beta 1$ expression in the glomerulus, osteopontin expression in the glomerulus and tubule, and TUNEL and ED-1-positive cells in the SHR-HF feno group.

Urinary levels and renal expression of 8-OH-dG, urinary levels of 8-epi-PGF $2 \alpha$ and serum and urinary levels of NOx

There were no differences in urinary $8-\mathrm{OH}-\mathrm{dG}$ or 8 -epi-PGF $2 \alpha$ levels between the SHR-NF group and the WKY-NF and WKY-HF rats.
However, there were significant increases in glomerular 8-OH-dGpositive cells and 24-h urinary $8-\mathrm{OH}-\mathrm{dG}$ and 8 -epi-PGF $2 \alpha$ in SHR-HF animals (Figures 7 and 8). This increased expression of $8-\mathrm{OH}-\mathrm{dG}$ in the glomerulus and elevated urinary concentrations of 8-OH-dG and 8 -epi-PGF $2 \alpha$ were significantly reduced in the SHR-HF feno group compared with those in the control SHR-HF group $(P<0.01$ and $P<0.001$, respectively). As shown in Figure 8, serum and urinary NOx concentrations were decreased in SHR-HF rats compared with those in SHR-NF rats. By contrast, these changes were not observed in the WKY-HF group. In the SHF-HF feno group, serum and urinary NOx concentrations were significantly increased with fenofibrate treatment $(P<0.01)$.

\section{Systolic BP and intrarenal biochemical characteristics}

As shown in Figure 9, intrarenal FFA and TG correlated positively with intrarenal AT II $(\gamma=0.63,0.36 ; P<0.001, P=0.040$, respectively) and 24-h urinary $8-\mathrm{OH}-\mathrm{dG}(\gamma=0.36,0.39 ; P=0.04,0.02$, respectively), and negatively with intrarenal $\operatorname{PPAR} \alpha$ contents $(\gamma=-0.47,-0.44$; $P=0.006,0.01$, respectively). Conversely, intrarenal $\operatorname{PPAR} \alpha$ contents correlated negatively with BP $(\gamma=-0.37, P=0.03)$, AT-II $(\gamma=-0.31$, $P=0.04)$ and 24 -h urinary $8-\mathrm{OH}-\mathrm{dG}(\gamma=-0.29, P=0.05)$. In addition, intrarenal AT-II strongly correlated with $\operatorname{SBP}(\gamma=0.71, P<0.001)$.
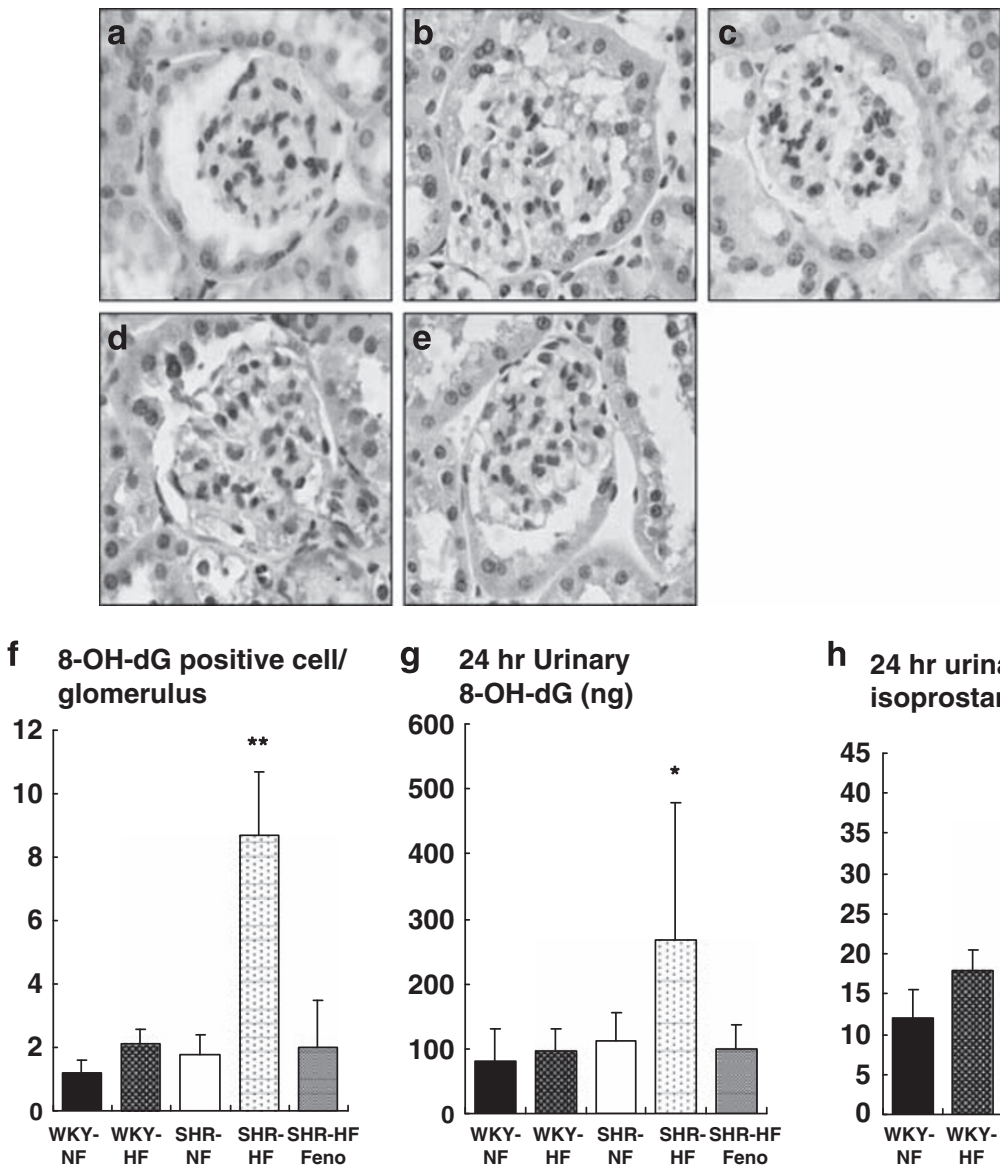

\section{h $24 \mathrm{hr}$ urinary isoprostane $(\mathrm{ng})$}

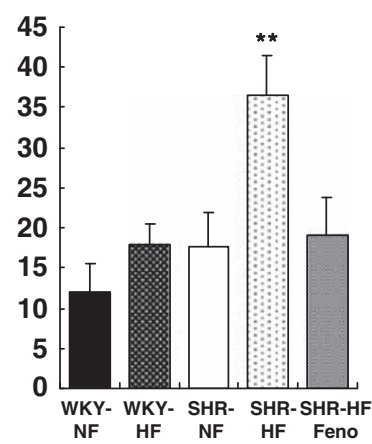

Figure 7 To determine oxidative stress in the kidneys, we measured 8-hydroxy-deoxyguanosine (8-OH-dG)-positive cells (dark brown) in the glomerulus as well as 24-h urinary concentrations of 8-OH-dG and 8-epi-PGF $2 \alpha$. Immunohistochemical staining for 8-OH-dG in the renal glomeruli in the Wistar-Kyoto (WKY) and spontaneously hypertensive (SHR) groups with a normal-fat diet (WKY-NF; a and SHR-NF; c) or a high-fat diet without treatment (WKY-HF, SHR$\mathrm{HF}$; $\mathbf{b}$ and d, respectively) or with fenofibrate (SHR-HF feno) treatment. (e) Quantitative assessment of 8-OH-dG-positive cells in the glomerulus (f) 24-h urinary concentration of $8-\mathrm{OH}-\mathrm{dG}(\mathrm{g})$ and 8 -epi- $\mathrm{PGF}_{2 \alpha}(\mathbf{h})$ in the study groups. ${ }^{*} P<0.01$ vs. the other groups, ${ }^{*} P<0.001$ vs. the other groups. A full color version of this figure is available at the Hypertension Research journal online. 


\section{a Plasma NOx (vM/mL)}

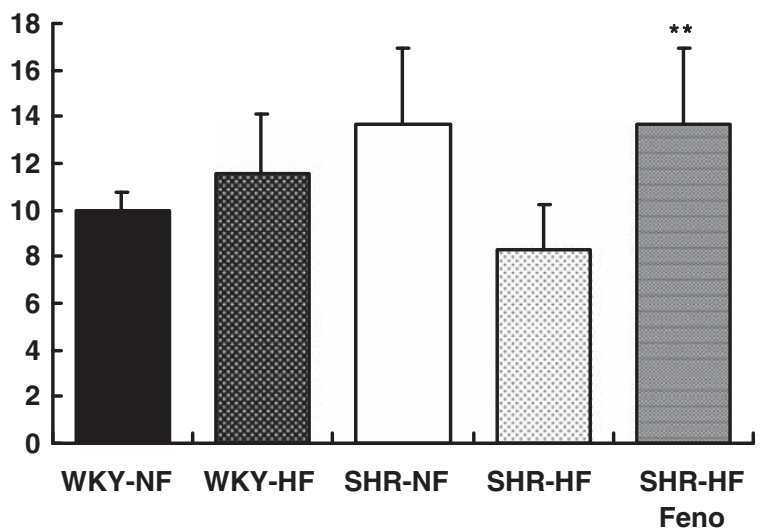

b Urinary NOx (vM/mg Cr)

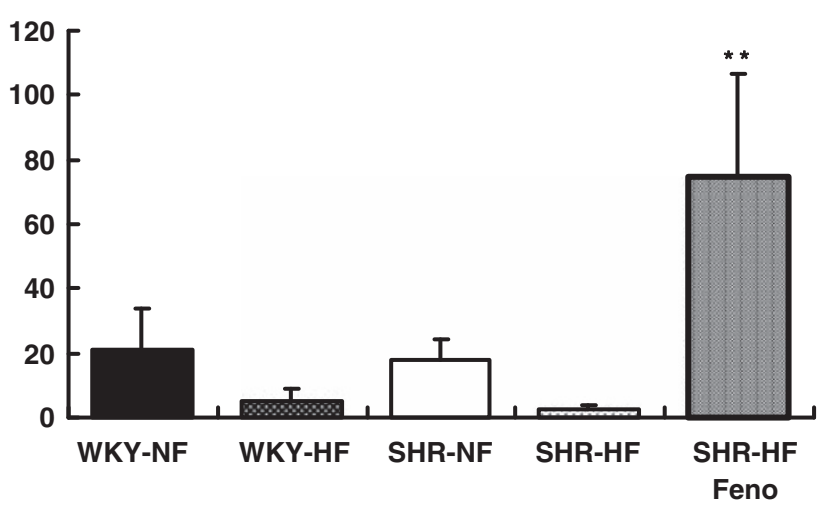

Figure 8 Plasma (a) and 24-h urinary (b) NOx concentrations at 12 weeks in the Wistar-Kyoto (WKY) and spontaneously hypertensive (SHR) groups with a normal-fat diet (WKY-NF and SHR-NF) or a high-fat diet without treatment (WKY-HF and SHR-HF) or with fenofibrate. ${ }^{*} P<0.01$ vs. the other groups, except the WKY-HF group, ${ }^{* *} P<0.01$ vs. the SHR-HF group.

However, 24-h urinary 8-OH-dG levels showed no correlation with intrarenal AT-II levels (data not shown).

\section{DISCUSSION}

We evaluated the role of fenofibrate in renal lipotoxicity by using an HF diet in genetically modified hypertensive SHR rats. This study clearly demonstrated that the elevated PPAR $\alpha$ expression in SHR control animals was markedly decreased in SHR-HF rats fed an HF diet, whereas the decreased renal expression of PPAR $\alpha$ in WKY rats was significantly increased in WKY-HF animals. These changes seem to be related to increased intrarenal TG and FFA accumulation. More severe structural changes (glomerulosclerosis and inflammation) and functional changes (hypertension and sodium retention) were noted in the SHR-HF group compared with that in other rats. Consistent with the changes in PPAR $\alpha$ and intrarenal lipid accumulation, RAS activation and oxidative stress associated with reduced NO bioavailability were more prominent in the SHR-HF group. However, no such differences were found between WKY-NF and WKY-HF rats. By contrast, fenofibrate decreased diet-induced gains of body weight, fat mass and systemic BP, improved insulin resistance and increased serum adiponectin concentrations in the SHR-HF group. Fenofibrate treatment in the SHR-HF group normalized intrarenal FFA and TG accumulation to the level of that of SHR-NF animals; this was associated with a normalization of the PPAR $\alpha$ expression in kidneys. Fenofibrate also exerted antihypertensive, anti-inflammatory and antifibrotic effects on the kidney in SHR-HF animals, and these benefits resulted from the prevention of lipotoxicity.

Several studies using an HF diet in SHR rats have addressed the question of whether this diet increases BP. ${ }^{27-29}$ Twenty-four hours radiotelemetry measurements by Sevoda et al. ${ }^{28}$ found an increase in poststress $\mathrm{BP}$ and under unstressed active conditions during the dark night phase after 12 weeks of an HF diet. They concluded that dietary obesity promotes the development of nocturnal hypertension. Another study using male Sprague-Dawley rats fed an HF diet for 10 weeks, also using the tail-cuff method, also showed significantly higher SBP owing to the downregulation of CYP4A and CYP2C23derived eicosanoid synthesis in the tubules. ${ }^{29}$ Consistent with these findings, we also found that an HF diet could increase BP in SHR rats.

Despite the comparatively small amount of food intake by these rats, there was more prominent intrarenal TG and FFA accumulation in the SHR-HF group compared with that in WKY-HF rats. To elucidate these discrepancies, we focused on the changes of $\operatorname{PPAR} \alpha$ in kidneys; PPAR $\alpha$ regulates the balance between energy production and utilization by regulating the expression of genes involved in fatty acid $\beta$-oxidation. ${ }^{16}$ PPAR $\alpha$ is also well known as a determinant of the development of hypertension and renal damage, especially in AT-II-induced hypertensive rats. ${ }^{21,23,24,30}$ Induction of the renal expression of CYP4A enzymes in the kidney using fibrate compounds has been reported to lower BP in SHR, stroke-prone SHR and Dahl salt-sensitive rats. ${ }^{31,32}$ We found the inverse pattern of PPAR $\alpha$ expression in kidneys of WKY-HF rats compared with that in SHR-HF animals. It is well known that despite severe hypertension, SHR rats are relatively resistant to renal injury. Markedly increased renal PPAR $\alpha$ expression in the SHR might have a protective role against hypertensive renal injury. In SHR-HF animals, fenofibrate activated the HF diet-induced suppression of PPAR $\alpha$ expression and reversed hypertension and renal damage. These findings suggest that PPAR $\alpha$ activation might have a direct role in diet-induced hypertension and renal damage in SHR rats.

Recently, local RAS, rather than systemic RAS, has been proposed to be a more important factor involved in the tissue damage that occurs with obesity or metabolic syndrome. ${ }^{7,33,34}$ In the case of diabetes mellitus, renal RAS is activated despite the suppression of circulating RAS. ${ }^{7}$ In addition, angiotensin-converting enzyme activity has been shown to be increased in the renal tissues of mice fed an HF diet. ${ }^{33}$ In our study, there were no differences in PRA and serum aldosterone concentrations in rats fed an HF diet compared with those in rats fed an NF diet. However, sodium retention and kaliuresis reflecting intrarenal RAS activity were remarkable in the SHR-HF group; these findings are consistent with a previous study by Granger et al. ${ }^{34}$ The levels of AT-II and the expression of protein and mRNA levels of RAS in renal tissues were significantly increased in the SHR-HF animals, and these levels were normalized by fenofibrate. Furthermore, PPAR $\alpha$ content in the kidney was negatively correlated with intrarenal AT-II concentrations. Thus, our results suggest that an HF diet-induced intrarenal RAS activation was associated with renal PPAR $\alpha$ activity.

The deleterious effect of lipotoxicity has been documented in multiple studies that established an association with obesity-related renal damage. ${ }^{35-39}$ In this study, we found excessive abnormal lipid accumulation in the renal tissue of SHR-HF animals compared with that in WKY-HF groups, which was related to increases in the mesangial matrix, TGF- $\beta 1$ expression, apoptotic glomerular cells and the infiltration of inflammatory cells into kidneys. These findings are consistent with those of previous studies showing that lipid 
a

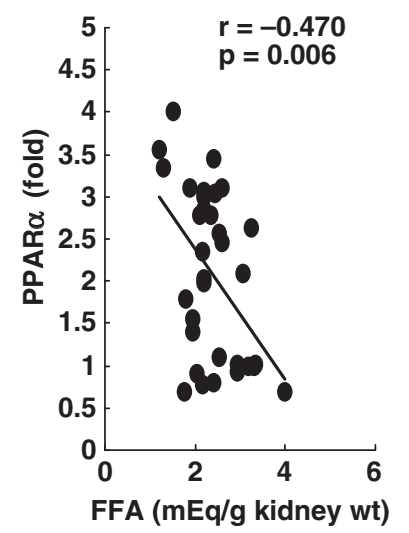

d

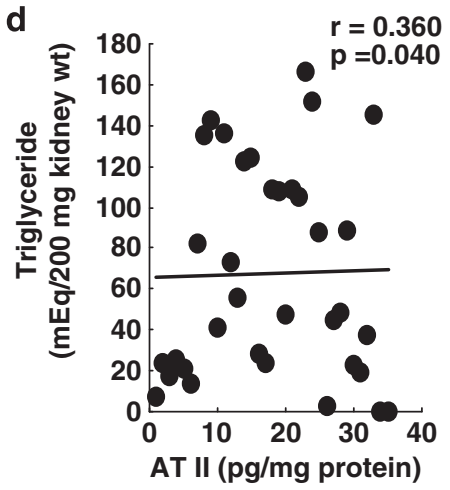

b
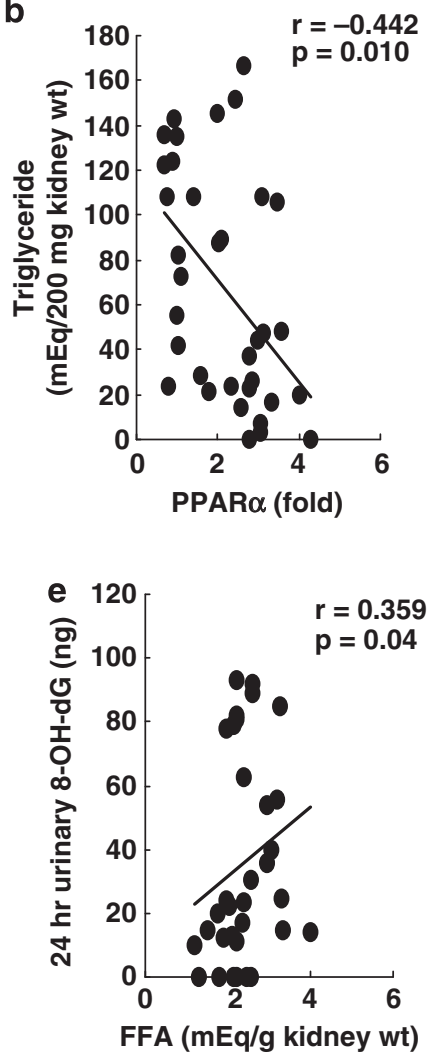

C

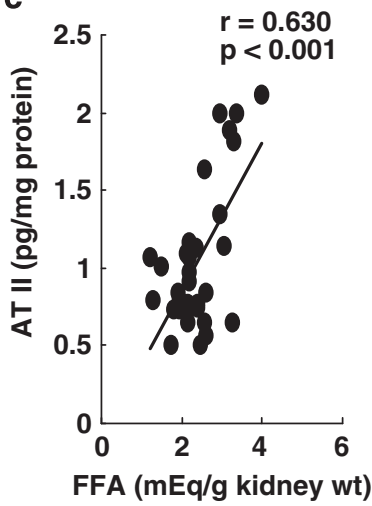

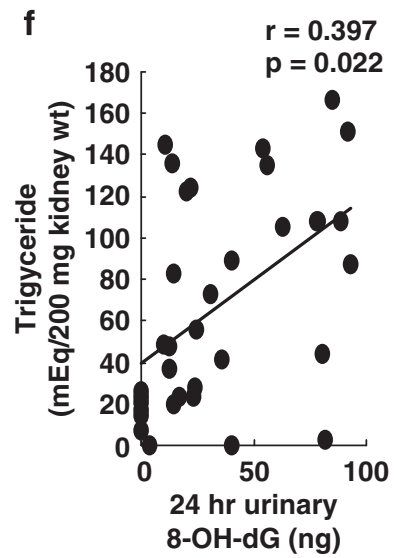

Figure 9 Relationships between intrarenal biochemical characteristics at 12 weeks of the Wistar-Kyoto (WKY) and spontaneously hypertensive (SHR) groups with normal-fat (NF) or high-fat (HF) diet. AT-II, intrarenal angiotensin II; FFA, intrarenal free fatty acid; PPAR $\alpha$, intrarenal peroxisome proliferator-activated receptor $\alpha$; 24-h urinary 8-OH-dG, 24-h urinary 8-hydroxy-deoxyguanosine.

accumulation in kidneys promotes glomerulosclerosis through the low-density lipoprotein-receptor in mesangial cells, through macrophage chemotaxis, increased production of fibrotic cytokines and direct podocyte injury through oxidative stress. ${ }^{40-44}$ These relationships are also supported by our finding that more lipid accumulated in the kidneys of SHR-HF rats than in those of WKY-HF rats, and they had more severe glomerulosclerosis and inflammatory cell infiltration.

Oxidative stress is both a cause and a consequence of hypertension and constitutes an additional stimulus for sodium retention in kidneys. It is also strongly correlated with intrarenal RAS activation in models of salt-sensitive hypertension and SHR. ${ }^{45}$ In addition, reactive oxygen species-associated augmentation of intrarenal angiotensinogen has an important part in the renal injury of genetically saltsensitive hypertensive animals and in diabetes in Zucker diabetic fat obese rats, as well as in patients with immunoglobulin A nephropathy. Previously, we found that PPAR $\alpha$ activity in kidneys was inversely correlated with lipid accumulation and oxidative stress in type 1 and 2 diabetic animals. ${ }^{21,22}$ In this study, we found that oxidative stress, as reflected by glomerular and 24 -h urinary $8-\mathrm{OH}-\mathrm{dG}$ and 8 -epi-PGF $2 \alpha$ levels, was closely related to intrarenal TG and FFA contents. Interestingly, fenofibrate treatment significantly improved reduced systemic and intrarenal bioavailability of $\mathrm{NO}$ and completely reversed the oxidative stress and inflammation in kidneys induced by the HF diet.

There is accumulating evidence that PPAR $\alpha$ activation is an effective therapy for obesity-related insulin resistance associated with lipid abnormalities. ${ }^{43}$ Consistent with previous findings, in this study, fenofibrate improved insulin resistance, dyslipidemia (such as decreased serum FFA and increased high-density lipoprotein-cholesterol) and adiponectin concentrations in SHR-HF animals. Adiponectin has been proposed to act as an antihypertensive adipokine by suppressing glucogenesis and stimulating fatty acid oxidation in the liver and muscle by activating the AMP kinase-PPAR $\alpha$ pathway. ${ }^{46}$ Consequently, hypoadiponectinemia causes endothelial dysfunction and activation of the inflammatory cascade, all of which are involved in the pathogenesis of hypertension. ${ }^{47}$ Therefore, it seems plausible that fenofibrate exhibits antihypertensive and renoprotective effects through, at least in part, its effect on improving dyslipidemia and increasing serum adiponectin levels.

In conclusion, PPAR $\alpha$ deficiency in the HF diet-induced obesity in genetic hypertensive SHR rats was associated with an increase in lipotoxicity in kidneys. Consequently, renal lipotoxicity probably contributed to the aggravation of BP and pathological changes by intrarenal RAS activation and oxidative stress. Activation of PPAR $\alpha$ with fenofibrate may effectively prevent obesity-induced lipotoxicity, hypertension and renal damage.

\section{ACKNOWLEDGEMENTS}

We acknowledge the financial support of the Catholic Medical Center Research Foundation and the Korean MSD for this work (5-2008-D0220-00002) (CW Park). This research was supported by the Basic Science Research Program 
through the National Research Foundation of Korea (NRF) funded by the Minister of Education, Science and Technology (R01-2009-0073171).

1 Kambham N, Markowitz GS, Valeri AM, Lin J, D'Agati VD. Obesity-related glomerulopathy: an emerging epidemic. Kidney Int 2001; 59: 1498-1509.

2 Rahmouni K, Correia ML, Haynes WG, Mark AL. Obesity-associated hypertension: new insights into mechanisms. Hypertension 2005; 45: 9-14.

3 Rocchini AP. Obesity hypertension. Am J Hypertens 2002; 15: 50S-52S.

4 Sarafidis PA, Bakris GL. Non-esterified fatty acids and blood pressure elevation: a mechanism for hypertension in subjects with obesity/insulin resistance? J Hum Hypertens 2007; 21: 12-21.

5 Dandona P, Mohanty P, Ghanim H, Aljada A, Browne R, Hamouda W, Prabhala A, Afzal $A$, Garg R. The suppressive effect of dietary restriction and weight loss in the obese on the generation of reactive oxygen species by leukocytes, lipid peroxidation, and protein carbonylation. J Clin Endocrinol Metab 2001; 86: 355-362.

6 Lin KY, Ito A, Asagami T, Tsao PS, Adimoolam S, Kimoto M, Tsuji H, Reaven GM, Cooke JP. Impaired nitric oxide synthase pathway in diabetes mellitus: role of asymmetrix dimethylarginine and dimetylarginine dimethylaminohydrolase. Circulation 2002; 106 987-992.

7 Bakker SJ, Ijzerman RG, Teerlink T, Westerhoff HV, Gans RO, Heine RJ. Cytosolic triglycerides and oxidative stress in central obesity: the missing link between excessive atherosclerosis, endothelial dysfunction, and beta-cell failure? Atherosclerosis 2000, 148: 17-21

8 Schaffer JE. Lipotoxicity: when tissues overeat. Curr Opin Lipidol 2003; 14: 281-287.

9 Shulman GI. Cellular mechanisms of insulin resistance. J Clin Invest 2000; 106: 171-176.

10 Fan Q, Liao J, Kobayashi M, Yamashita M, Gu L, Gohda T, Suzuki Y, Wang LN, Horikosh $\mathrm{S}$, Tomino $\mathrm{Y}$. Candensartan reduced advanced glycation end products accumulation and diminished nito-oxidative stress in type 2 diabetic KK/Ta mice. Nephrol Dial Transplant 2004; 19: 3012-3020.

11 Nangaku M, Miyata T, Sada T, Mizuno M, Inagi R, Ueda Y, Ishikawa N, Yuzawa H, Koike $\mathrm{H}$, van Ypersele de Strihou C, Kurokawa K. Anti-hypertensive agents inhibit in vivo the formation of advanced glycation end products and improve renal damage in a type 2 diabetic nephropathy rat model. J Am Soc Nephrol 2003; 14: 1212-1222.

12 Sonta $T$, Inoguchi $T$, Matsumoto $S$, Yasukawa $K$, Inuo M, Tsubouchi H, Sonoda N, Kobayashi K, Utsumi $\mathrm{H}$, Nawata $\mathrm{H}$. In vivo imaging of oxidative stress in the kidney of diabetic mice and its normalization by angiotensin II type 1 receptor blocker. Biochem Biophys Res Commun 2005; 330: 415-422.

13 Paul M, Poyan MA, Kreutz R. Physiology of local renin-angiotensin systems. Physiol Rev 2006; 86: 747-803

14 Goossens GH, Blaak EE, van Baak MA. Possible involvement of the adipose tissue renin-angiotensin system in the pathophysiology of obesity and obesity-related disorders. Obes Rev 2003; 4: 43-55.

15 Hall JE, Brands MW, Henegar JR. Mechanisms of hypertension and kidney disease in obesity. Ann NY Acad Sci 1999; 892: 91-107.

16 Guan Y. Peroxisome proliferator-receptive activator family and its relationship to renal complications of the metabolic syndrome. J Am Soc Nephrol 2004; 15: 2801-2815.

17 Costet P, Legendre C, More J, Edgar A, Galtier P, Pineau T. Peroxisome proliferatoractivated receptor alpha-isoform deficiency leads to progressive dyslipidemia with sexual dimorphic obesity and steatosis. J Biol Chem 1998; 273: 29577-29585.

18 Diep QN, Touyz RM, Schiffrin EL. Docosahexaenoic acid, a peroxisome proliferatoractivated receptor-alpha ligand, induces apoptosis in vascular smooth muscle cells by stimulation of p38 mitogen-activated protein kinase. Hypertension 2000; 36: 851-855.

19 Kintscher U, Lyon C, Wakino S, Bruemmer D, Feng X, Goetze S, Graf K, Moustakas A, Staels B, Fleck E, Hsueh WA, Law RE. PPARalpha inhibits TGF-beta-induced beta5 integrin transcription in vascular smooth muscle cells by interacting with Smad4. Circ Res 2002: 91: e35-e44.

20 Diep QN, Amiri F, Touyz RM, Cohn JS, Endemann D, Neves MF, Schiffrin FL. PPARalpha activator effects on Ang II-induced vascular oxidative stress and inflammation. Hypertension 2002; 40: 866-871.

21 Park CW, Kim HW, Ko SH, Chung HW, Lim SW, Yang CW, Chang YS, Sugawara A, Guan $\mathrm{Y}$, Breyer M. Accelerated diabetic nephropathy in mice lacking the peroxisome proliferator-activated receptor $\alpha$. Diabetes 2006; 55: 885-893.

22 Park CW, Zhang Y, Cha DR, Su D, Hwang MT, Fan XF, Davis L, Striker G, Zheng F, Breyer $\mathrm{MD}$, Guan YF. PPAR $\alpha$ agonist fenofibrate improves diabetic nephropathy in $\mathrm{db} / \mathrm{db}$ mice. Kidney Int 2006; 69: 511-517.
23 Vera T, Taylor M, Bohman Q, Flasch A, Roman RJ, Stec DE. Fenofibrate prevents the development of angiotensin II-dependent hypertension in mice. Hypertension 2005; 45: 703-735.

24 Zhao X, Li LY. PPAR- $\alpha$ agonist fenofibrate induces renal CYP enzymes and reduces blood pressure and glomerular hypertrophy in Zucker diabetic fatty rats. Am J Nephrol 2008; 28: 598-606.

25 Delaney B, Nicolosi RJ, Wilson TA, Carlson T, Frazer S, Zheng GH, Hess R, Ostergren K, Haworth J, Knutson N. Beta-glucan fractions from barley and oats are similarly antiatherogenic in hypercholesterolemic Syrian golden hamsters. J Nutr 2003; 133 : 468-475.

26 Fukada M, Kato S, Miyoshi M, Yamaguchi K, Imoto T, Watanabe T. Systemic administration of lipopolysaccharide upregulates angiotensin II expression in rat renal tubules: immunohistochemical and ELISA studies. Peptides 2005; 26: 2215-2221.

27 Knight SF, Quigley JE, Yuan J, Roy SS, Elmarakby A, Imig JD. Endothelial dysfunction and the development of renal injury in Spontaneously hypertensive rats fed a high-fat diet. Hypertension 2008; 51: 352-359.

28 Sevoda L, Berude J, Gudet D, Dumont M, Tremblay J, Hamet P, Pausova Z. Dietinduced obesity delays cardiovascular recovery from stress in spontaneously hypertensive rats. Obes Res 2004; 12: 1951-1958

29 Wang MH, Smith A, Zhou Y, Chang HH, Lin S, Zhao X, Imig JD, Dorrance AM Downregulation of renal CYP-derived eicosanoid synthesis in rats with diet-induced hypertension. Hypertension 2003; 42: 592-599.

30 Barton M, Carmona R, Morawietz H, d'Uscio LV, Goettsch W, Hillen H, Haudenschild CC, Krieger JE, Munter K, Lattmann T, Luscher TF, Shaw S. Obesity is associated with tissue-specific activation of renal angiotensin-converting enzyme in vivo: evidence for a regulatory role of endothelin. Hypertension 2000; 35: 329-336.

31 Roman RJ, Ma YH, Frohlich B, Markham B. Clofibrate prevents the development of hypertension in Dahl salt-sensitive rats. Hypertension 1993; 21: 985-988.

32 Shatara RK, Quest DW, Wilson TW. Fenofibrate lowers blood pressure in two genetic models of hypertension. Can J Physiol Pharmacol 2000; 78: 367-371.

33 Boustany CM, Bharadwaj K, Daugherty A, Brown DR, Randall DC, Cassis LA. Activation of the systemic and adipose renin-angiotensin system in rats with diet-induced obesity and hypertension. Am J Physiol Regul Integr Comp Physiol 2004; 287: R943-R949.

34 Granger JP, West D, Scott J. Abnormal pressure natriuresis in the dog model of obesityinduced hypertension. Hypertension 1994; 23 (1 Suppl): |8-I11.

35 Chander PN, Gealekman O, Brodsky SV, Elitok S, Tojo A, Crabtree M, Gross SS, Goligorsky MS. Nephropathy in Zucker diabetic fat rat is associated with oxidative and nitrosative stress: prevention by chronic therapy with a peroxynitrite scavenger ebselen. J Am Soc Nephrol 2004; 15: 2391-2403.

36 Jiang T, Wang Z, Proctor G, Moskowitz S, Liebman SE, Rogers T, Lucia MS, Li J, Levi M. Diet-induced obesity in C57BL/6J mice causes increased renal lipid accumulation and glomerulosclerosis via a sterol regulatory element-binding protein-1c-dependent pathway. J Biol Chem 2005; 280: 32317-32325.

37 Lee HS, Lee JS, Koh HI, Ko KW. Intraglomerular lipid deposition in routine biopsies. Clin Nephrol 1991; 36: 67-75.

38 Watanabe S, Tagawa T, Yamakawa K, Shimabukuro M, Ueda S. Inhibition of the reninangiotensin system prevents free fatty acid-induced acute endothelial dysfunction in humans. Arterioscler Thromb Vasc Biol 2005; 25: 2376-2380.

39 Mack CM, Moore CX, Jodka CM, Bhavsar S, Wilson JK, Hoyt JA, Roan JL, Vu C, Laugero KD, Parkes DG, Young AA. Antiobesity action of peripheral exenatide (exendin-4) in rodents: effects on food intake, body weight, metabolic status and side-effect measures. Int J Obes (Lond) 2006; 30: 1332-1340.

40 Henegar JR, Bigler SA, Henegar LK, Tyagi SC, Hall JE. Functional and structural changes in the kidney in the early stages of obesity. J Am Soc Nephrol 2001; 12: 1211-1217.

41 Joles JA, Kunter U, Janssen U, Kriz W, Rabelink TJ, Koomans HA, Floege J. Early mechanisms of renal injury in hypercholesterolemic or hypertriglyceridemic rats. J Am Soc Nephrol 2000; 11: 669-683.

42 Kasiske BL, Crosson JT. Renal disease in patients with massive obesity. Arch Intern Med 1986; 146: 1105-1109.

43 Rodriguez-Iturve B, Romero F, Johnson RJ. Pathophysiological mechanisms of saltdependent hypertension. Am J Kidney Dis 2007; 50: 655-672.

44 Tsunoda M, Kobayashi N, Ide T, Utsumi M, Nagasawa M, Murakami K. A novel PPAR agonist ameliorates insulin resistance in dogs fed a high-fat diet. Am J Physiol Endocrinol Metab 2008; 294: E833-E840.

45 Kobori H, Nishiyama A. Effects of tempol on renal angiotensinogen production in Dahl salt-sensitive rats. Biochem Biophys Res Commun 2004; 315: 746-750.

46 Kadowaki T, Yamauchi T, Kubota N, Hara K, Ukei K. Adioponectin and adiponectin receptors in obesity-linked insulin resistance. Norvatis Found Symp 2007; 286: $164-176$

47 Schillaci G, Pirro M. Hypoadiponectinemia: a novel link between obesity and hypertension? Hypertension 2007; 49: 1217-1219. 